\title{
关于推荐审稿人的几条建议
}

曹守波

哈尔滨医科大学附属肿瘤医院

同行评审 (peer review) 是 SCI 期刊审稿的主流 模式, 很多杂志往往会要求投稿人推荐审稿人, 而 选择合适的审稿人, 审稿的流程也会相对省时省力。 对于杂志社来说, 审稿人的选定一般会有两种, 如 果杂志社有推荐审稿人这一栏, 一般都会要求推荐 不止一个审稿人, 这时候你可以选择稍微多一些的 审稿人给杂志社备选, 毕竟有些审稿人可能会由于个 人原因拒绝审稿。即使是我们推荐了审稿人, 杂志 社有时候也不保证一定会采用我们推荐的审稿人。

对于审稿人的推荐, 我个人会选择从看过的文献 中选择, 这样比较节省时间, 避免花费大量时间来 搜集审稿人。另外一种就是杂志社会自己选择审稿人, 有过投稿经验的可能会了解, 在杂志社注册的时候会 有一个选项问是否同意成为杂志社的审稿人, 以及涉 及研究领域等问题, 如果你选择同意的话, 后续如果 有该领域稿件, 杂志社就有可能会邀请你作为审稿人。 关于如何推荐审稿人, 相信仁者见仁, 智者见智, 接 下来我针对如何推荐审稿人谈谈个人的看法。

\section{1. 选择同研究领域的专家作为审稿人}

所谓同行评审, 就是指推荐研究领域相同的专 家进行审稿, 这样推荐的审稿人对稿件比较熟悉, 审阅起来也相对得心应手。反之, 如果选择研究领 域不同的专家, 首先他对稿件的研究内容不一定非 常熟悉, 毕竟研究领域不一定会存在交叉, 其次, 你推荐的审稿人有可能不会被杂志社采用, 即使采 用的话, 审稿人也很有可能会因为研究领域存在差 异而拒绝审稿, 反而会增加审稿花费的时间。

\section{2. 选择研究领域具有延续性的专家作为审 稿人}

对于这一点, 我的理解是, 推荐的审稿人在研
究内容上有延续性, 最近一直在从事该项课题的研 究, 因此对该领域的前沿会比较熟悉, 能够较好地 把握稿件研究内容的优劣, 给予客观的意见。

\section{3. 尽量选择该领域的非顶尖专家作为审稿 人}

推荐审稿人的其中一个优点就是能够帮助杂志 较快地找到合适的审稿人, 以便尽快反馈稿件的状 态。我们平时都会有一个共识, 那就是, 老板很忙, 平时跟老板反馈的一些问题不一定能得到及时处理, 各研究领域的顶尖专家相信都一样, 每天忙于各种 学术会议、课题讨论等等, 抽出审稿的时间相信会 少一些, 如果个人认为自己的稿件水平很高, 也提 倡推荐给这些专家, 希望他们能提出些建设性意见。 相反, 如果选择非顶尖专家审稿人, 相信他们会相 对更愿意也有时间为杂志审稿, 这对他们来说也是了 解目前研究现状的一个好机会, 说不定能够碰撞出 新思路。

\section{4. 选择研究支持自己结论的专家作为审稿 人}

对此, 我一般会选择推荐稿件参考文献的专家 作为审稿人。其实, 这一点相对没有那么重要, 我 个人认为只要你有充足的实验和结果支持, 能够自 圆其说, 把现象及原因解释得很透彻, 推荐和自己 研究结果一致与否的专家作为审稿人并不是问题。另 外, 推荐审稿人时, 一般要包括审稿人的姓名、单 位及邮箱, 这些内容在已发表的文章都会有, 我一 般会自己建一个Word 文档, 把这些信息粘贴到一起, 方便投稿用。

以上就是我个人对推荐审稿人的看法, 欢迎大 家批评指正。 